\title{
Revitalisasi bahasa Indonesia dalam konteks kebahasaan
}

\section{Indonesia language revitalization in language context}

\author{
Ni Wayan Sartini \\ Fakultas Ilmu Budaya, Universitas Airlangga \\ E-mail: yaniwiratha@yahoo.com
}

\begin{abstract}
Bahasa Indonesia today faces many misuse in its daily usage. The language disorder appears on many aspects on language usage, such as excessive and misguided use of foreign languages, violation of the rules of Bahasa Indonesia in media and in public places, the inclusion of regional language structure, use of acronyms arbitrarily, the emergence of slank language and so on. Regarding the language disorder, there is a strong need of revitalization of Bahasa Indonesia in linguistic context. Revitalization means re-positioning Indonesian on its right place and return its existing language rules. Revitalization of Indonesian is expected to overcome language misuse, expected to reduce the chaos or even eliminate them. Using Bahasa Indonesia correctly and appropriately means modelling the right stance to the only official language in this country.
\end{abstract}

Keywords: Indonesian language, chaotic, revitalitation

\begin{abstract}
Abstrak
Bahasa Indonesia saat ini banyak menghadapi penyalahgunaan dalam penggunaan sehari-hari. Kekacauan bahasa ini tampak pada beberapa hal, antara lain penggunaan bahasa asing yang berlebihan dan salah kaprah, pelanggaran terhadap kaidah-kaidah bahasa Indonesia di media dan di tempat-tempat umum, masuknya struktur bahasa daerah, penggunaan akronim yang sewenang-wenang, munculnya bahasa anak muda, dan sebagainya. Dengan kekacauan itu, revitalisasi harus dilakukan dalam konteks kebahasaan. Revitalisasi berarti mendudukkan posisi yang benar kepada bahasa Indonesia dan kembali kepada kaidah-kaidah bahasa yang ada dalam bahasa Indonesia. Upaya revitalisasi terhadap bahasa Indonesia diharapkan dapat menyelesaikan segala kekacauan yang ada selama ini, sehingga dapat mengurangi bahkan menghilangkan kekacauan tersebut. Dengan menggunakan bahasa Indonesia yang baik dan benar berarti memberikan posisi yang benar kepada satu-satunya bahasa resmi di negeri ini.
\end{abstract}

Kata kunci: bahasa Indonesia, kacau, revitalisasi

\section{Pendahuluan}

Bahasa Indonesia memiliki sejarah yang panjang dalam mencapai posisinya seperti saat ini. Kehadiran bahasa Indonesia adalah hasil perjalanan sejarah yang panjang. Dimulai dari bahasa Melayu yang berkembang di wilayah semenanjung Melayu, Sumatera, dan Kalimantan, kemudian berkembang terus hampir tanpa gangguan menuju bentuk akhirnya, yaitu bahasa Indonesia. Bahasa Indonesia berjalan dalam satu untaian sejarah yang panjang, yang walaupun dicoba digagalkan oleh kekuasaan kolonial, namun tetap bertahan kemudian muncullah dengan nama baru, yaitu bahasa Indonesia.

Faktor-faktor seperti (1) kemantapan bahasa Melayu sebagai lingua franca; (2) kuatnya semangat nasionalisme; (3) tersedianya ahli-ahli bahasa yang penuh dedikasi; (4) sifat demokratis dan mobilitas bahasa Melayu; dan (5) terjaganya pertumbuhan alam pikiran atas dasar kosmologi sendiri; menjadi tiang-tiang historis utama yang membuat Indonesia sebagai satu-satunya bangsa di dunia yang tetap memiliki bahasa secara utuh (Pabottinggi 1996). Walaupun begitu, kaum penjajah dan para pendukungnya di kalangan bumi putra tiada hentinya meniupkan bahwa Indonesia adalah bahasa yang tidak memiliki otoritas, sebuah bahasa yang kacau. 
Bahasa Indonesia adalah bahasa yang terpenting di kawasan Republik Indonesia. Pentingnya peranan bahasa itu antara lain bersumber pada ikrar ketiga Sumpah Pemuda 1928 yang berbunyi: "Kami poetera dan poeteri Indonesia mendjoendjoeng bahasa persatuan, bahasa Indonesia" dan pada Undang-Undang Dasar 1945, Bab XV, Pasal 36 yang di dalamnya tercantum pasal khusus yang menyatakan bahwa "Bahasa negara ialah bahasa Indonesia" (Alwi, Dardjowidjojo, Lapoliwa, \& Moeliono 1998:1). Kedua hal itu memberikan dasar yang kuat dan resmi bagi pemakaian bahasa Indonesia tidak hanya sebagai bahasa perhubungan pada tingkat nasional, tetapi juga sebagai bahasa resmi kenegaraan. Faktor-faktor lain yang mendukung mengapa bahasa Indonesia menduduki tempat yang sangat penting di antara ratusan bahasa daerah yang ada di wilayah Nusantara ini adalah jumlah penutur, luas penyebaran, dan peranannya sebagai sarana ilmu, seni sastra, dan pengungkap budaya.

Sejak dikumandangkannya Sumpah Pemuda 28 Oktober 1928, bahasa Indonesia telah menjadi salah satu pilar bangsa Indonesia untuk menyatukan bangsa Indonesia yang terdiri atas berbagai latar belakang kelompok, suku bangsa, bahasa, agama, dan budaya. Selama 85 tahun, sejak Sumpah Pemuda dikumandangkan memang telah terbukti bahwa bahasa Indonesia telah menjadi alat komunikasi dalam keberagaman tersebut. Bahasa Indonesia tidak hanya dituturkan oleh masyarakat perkotaan, tetapi juga oleh masyarakat yang tinggal di pedesaan.

Kongres Bahasa yang pertama pada tahun 1938 menegaskan bahwa bahasa Indonesia dikukuhkan sebagai bahasa resmi dan bahasa pengantar di dalam badan perwakilan dan perundangan (Moeliono 1981). Sebagai bahasa nasional, bahasa Indonesia adalah lambang kebulatan semangat kebangsaan Indonesia, alat penyatuan berbagai-bagai masyarakat yang berbeda-beda latar belakang kebahasaan, kebudayaan, dan kesukuannya ke dalam satu masyarakat nasional Indonesia, dan alat perhubungan antarsuku, antardaerah serta budaya. Dalam kedudukannya sebagai bahasa negara, bahasa Indonesia adalah bahasa resmi pemerintahan, bahasa pengantar di dalam dunia pendidikan, alat perhubungan pada tingkat nasional untuk kepentingan perencanaan dan pelaksanaan pembangunan nasional, serta alat pengembangan kebudayaan, ilmu pengetahuan dan teknologi.

Posisi bahasa Indonesia diperkuat dengan UU RI NO 24 Tahun 2009 tentang Bendera, Bahasa, dan Lambang Negara, serta lagu kebangsaan antar lain dalam pasal 25 yang menyatakan (1) Bahasa Indonesia yang dinyatakan sebagai bahasa resmi negara dalam Pasal 36 Undang-Undang Dasar Negara Kesatuan Republik Indonesia Tahun 1945 bersumber dari bahasa yang diikrarkan dalam Sumpah Pemuda tanggal 28 Oktober 1928 sebagai bahasa persatuan yang dikembangkan sesuai dengan dinamika peradaban bangsa; (2) Bahasa Indonesia sebagaimana dimaksud pada ayat 1 berfungsi sebagai jati diri bangsa, kebanggaan nasional, sarana pemersatu berbagai suku bangsa, serta sarana komunikasi antardaerah dan antarbudaya daerah, ayat 3 Bahasa Indonesia sebagai bahasa resmi negara sebagaimana dimaksud pada ayat 1 berfungsi sebagai bahasa resmi kenegaraan, pengantar pendidikan, komunikasi tingkat nasional, pengembangan kebudayaan nasional, transaksi dan dokumentasi niaga, serta sarana pengembangan dan pemanfaatan ilmu pengetahuan, teknologi, seni, dan bahasa media massa.

Pasal 26 UU RI NO 24 Tahun 2009 menyatakan, bahasa Indonesia wajib digunakan dalam peraturan perundang-undangan, pasal 27 menyatakan bahasa Indonesia wajib digunakan dalam dokumen resmi Negara. Pasal 28 menegaskan bahasa Indonesia wajib digunakan dalam pidato resmi Presiden, Wakil Presiden, dan pejabat negara yang lain yang disampaikan di dalam atau di luar negeri. Pasal 29 ayat 1 bahasa Indonesia wajib digunakan sebagai bahasa pengantar dalam pendidikan nasional.

Dari beberapa perundangan yang telah mengokohkan posisi bahasa Indonesia tersebut, tidak seorang pun dapat menyangkal posisi bahasa Indonesia sebagai satu-satunya bahasa resmi di negeri ini. Perjalanan panjang yang telah dilalui bahasa Indonesia sampai saat ini, tak seorang pun juga dapat menyangkal atas kemajuan pesat yang telah dicapai oleh bahasa Indonesia. Dalam puluhan tahun yang lalu, bahasa Indonesia telah berkembang dari bahasa politik untuk menggalang kekuatan dalam perjuangan antikolonialisme, sebagai pernyataan keyakinan dan tekad bangsa Indonesia untuk hidup sebagai suatu bangsa yang merdeka. Bahasa Indonesia menjadi bahasa negara dan bahasa nasional yang cukup mampu untuk menampung dan mengungkapkan segala keperluan kehidupan negara. 
Secara umum bahasa Indonesia memiliki peranan sebagai wahana modernisasi dan alat penguasaan dan pembinaan ilmu pengetahuan dan teknologi. Bahasa Indonesia sudah merupakan wahana kemajuan sosial (upward mobility) dan perluasan komunikasi (language of wider comunication). Perluasan kemampuan bahasa tidak hanya di bidang hukum, ilmu-ilmu sosial dan ilmu-ilmu lain, tetapi juga di bidang kesastraan, peningkatan kemampuan ekspresif dalam mengucapkan berbagai perasaan halus dan kekayaan batin dalam karya-karya sastra dan sajak-sajak moderen, semua telah menunjukkan vitalitas dan kreativitas bahasa Indonesia yang hampir-hampir menakjubkan (Soedjatmoko 1996).

\section{Potret bahasa Indonesia masa kini}

Globalisasi yang melanda dunia saat ini berpengaruh pada perkembangan bahasa di seluruh dunia. Terjadi penyerapan berbagai unsur dari berbagai bahasa akibat kemajuan teknologi. Tidak terkecuali bangsa dan bahasa Indonesia. Budaya Indonesia yang terbuka dan toleran, membawa dampak terbukanya juga bahasa Indonesia menerima segala pengaruh kebahasaan baik dari asing maupun dari unsur-unsur bahasa daerah. Bahasa Indonesia saat ini dikatakan sebagai sebagai sebuah keranjang sampah yang menampung segala kosa kata dari berbagai bahasa tanpa melalui proses-proses yang ada dalam kaidah-kaidah bahasa Indonesia. Akibatnya, bahasa Indonesia kini dipenuhi oleh berbagai unsur asing dan daerah yang digunakan secara bersama-sama dan bercampur aduk dalam komunikasi masyarakat Indonesia. Akhirnya, terbentuklah pola-pola komunikasi masyarakat Indonesia seperti saat ini.

Potret bahasa Indonesia saat ini adalah potret bahasa yang kacau. Kacau dalam dalam aspek kosa kata, semantik, struktur. Tidaklah salah ketika penjajah dan para pendukungnya mengatakan bahasa Indonesia adalah bahasa yang tidak memiliki otoritas dan bahasa yang kacau. Ada beberapa butir yang dapat diidentifikasi, yaitu; 1) Penggunaan bahasa Inggris secara berlebihan atau secara salah kaprah. Contoh yang nyata adalah nama-nama toko, nama-nama gedung, perumahan mewah, pusatpusat hiburan, iklan-iklan, slogan-slogan, acara-acara televisi, usaha-usaha di perkampungan dan sebagainya. Dalam berbicara pun selalu menyelipkan kata-kata bahasa Inggris. Gejala seperti ini oleh Ben Anderson (1982) disebut "Indoglish". Sebagai contoh penggunaan kata dalam bahasa Inggris event telah berubah menjadi epen. Kekeliruan terletak pada berubahnya konsonan /v/ menjadi /p/ karena disesuaikan dengan lafal masyarakat Indonesia. Kata ini telah menjadi kata yang lazim digunakan masyarakat Indonesia tanpa benar-benar paham makna dan ucapannya, 2) Pelanggaran kaidah-kaidah bahasa Indonesia baik di media massa maupun di tempat-tempat umum. Sering dijumpai ketidakmampuan dalam membedakan kata depan di dan awalan di-, penggunaan walaupun, namun, sehingga dan sebagainya, 3) Masuknya struktur kalimat bahasa daerah ke dalam bahasa Indonesia yang tidak sesuai dengan kaidah kalimat dalam bahasa Indonesia. Kata "sepertinya" digunakan untuk mengganti kata "seolah-olah" dan sebagainya, 4) Meluasnya kecenderungan menggunakan akronim secara sewenang-wenang dan membingungkan masyarakat, apalagi kalau dua akronim untuk pengertian yang sama digunakan untuk merebut tempat dalam bahasa Indonesia. Contoh: "lansia" dan "manula", 5) Munculnya bahasa-bahasa anak muda (remaja) yang disebut bahasa gaul dengan berbagai proses pembentukannya yang unik. Mengadopsi berbagai bahasa baik bahasa daerah maupun bahasa asing kemudian disesuaikan dengan lafal anak muda atau bahkan pengucapannya dibalik. Sebagai contoh; kata slow dibaca sesuai lafal masyararakat Indonesia selow dan menjadi bahasa gaul (anak muda) woles karena dibaca dari kiri ke kanan. Bunyi sangat berperan dalam pembentukan bahasa gaul. Bahasa gaul cius me apa jika direkonstruksi berasal dari "Serius, demi apa?' yang pelafalannya sesuai dengan lafal anak-anak, 6) Bahasa birokrasi memiliki tipe tersendiri yaitu singkat dengan jargon-jargon khusus. Bahasa tersebut merembes jauh menjangkau tingkat terendah. Gaya bahasa ini menampilkan latar belakang etnis dan kultur para pemakai. Bahasa birokrasi ini biasanya berupa peniruan terhadap bahasa yang digunakan oleh atasan, 7) Munculnya berbagai kata, jargon, dan frasa-frasa baru dalam bahasa politik setiap pesta demokrasi di Indonesia. Bahasa Indonesia pada era Orde Baru mengalami proses kramanisasi atau mengalami eufemisme yakni penghalusan makna. Kata-kata bahasa Indonesia pada era ini telah kehilangan makna alamiahnya karena telah diganti dengan makna-makna kias yang jauh dari makna dasarnya. 
Sugono (1997) mengatakan kesalahan-kesalahan dalam bahasa Indonesia dapat dikategorikan; (a) kesalahan ejaan; (b) kesalahan diksi; dan (c) kesalahan struktur. Kesalahan-kesalahan tersebut kadang dianggap sebagai suatu hal yang biasa, karena yang terpenting adalah maknanya dapat tersampaikan dengan baik. Sikap itu dapat menambah kacaunya bahasa Indonesia.

Dengan kekacauan yang terjadi dalam bahasa Indonesia sekarang ini, apa yang salah pada bangsa Indonesia? Dalam interospeksi, harus ditelusuri apa yang menjadi penyebabnya. Jika bahasa Indonesia berkembang seperti sekarang ini, itu dikarenakan dinamika politik tertinggi di negeri ini memang tidak melindunginya. Energi terbaiknya terserap habis untuk menjaga stabilitas politik demi tingkat pertumbuhan ekonomi yang tinggi. Seolah-olah bangsa ini bisa tegak tanpa kecintaan yang tulus pada simbol-simbol utamanya. Begitulah, maka bahasa Indonesia kini tidak memiliki otoritas.

\section{Revitalisasi bahasa Indonesia}

Upaya merevitalisasi bahasa Indonesia dapat dimaknai sebagai strategi untuk menjadikan bahasa Indonesia kembali pada posisi semula sebagai bahasa resmi negara. Secara konstitusi, posisi bahasa Indonesia sesungguhnya sudah sangat jelas dan kuat kedudukannya sebagai bahasa negara Indonesia. UUD Negara Republik Indonesia Tahun 1945 Pasal 36 jelas menyebutkan bahwa "Bahasa negara ialah Bahasa Indonesia". Kedudukan bahasa Indonesia semakin diperkuat dengan terbitnya UU RI NO 24 TAHUN 2009 tentang Bendera, Bahasa, dan Lambang Negara, serta Lagu Kebangsaan (Listiono 2013). Hal itu merupakan upaya revitalisasi dalam konteks sosial yakni meluruskan kembali posisi bahasa Indonesia sebagai bahasa negara.

Dalam konteks kebahasaan atau linguistik revitalisasi berarti menghidupkan kembali atau memberikan vitalitas atau energi baru pada bahasa Indonesia, sehingga dapat kembali pada normanorma atau kaidah-kaidah yang telah ditetapkan sebagai acuan berbahasa yang benar. Kekacauan bahasa yang terjadi dalam bahasa Indonesia dan sikap acuh tak acuh terhadap bahasa Indonesia menyebabkan terpuruknya bahasa Indonesia yang telah diperjuangkan dengan proses yang sangat panjang. Apa yang telah menjadi simbol negara tersebut seakan-akan tidak pernah mendapat perhatian dan penghargaan. Perkembangannya yang "liar" tanpa kendali menjadikan bahasa Indonesia sebagai sebuah keranjang sampah yang menampung kata-kata tanpa prosedur penyerapan yang benar. Dalam kenyataannya, bahasa Indonesia menerima kata-kata asing yang sebenarnya telah ada dalam bahasa Indonesia. Itulah sebabnya, mengapa banyak sekali kata-kata kembar dalam bahasa Indonesia. Katakata kembar ini bersaing di masyarakat dan masyarakatlah yang menjadi penentu kata-kata yang mana lebih dominan digunakan dalam berkomunikasi baik lisan maupun tulisan.

Usaha-usaha untuk merevitalisasi bahasa Indonesia telah banyak dilakukan. Dengan memberikan pelajaran atau kuliah-kuliah bahasa Indonesia diharapkan dapat merevitalisasi bahasa Indonesia. Bahasa Indonesia harus diajarkan di segala jenjang pendidikan agar bahasa Indonesia tidak menjadi asing di negerinya sendiri, bahasa Indonesialah yang menduduki tempat terhormat dalam seluruh kegiatan komunikasi nasional maupun lokal di negara Indonesia. Otoritas bahasa mustahil ditegakkan tanpa pelaksanaan dan kerja sama berbagai pihak. Tidak berlebihan kiranya, apa yang dikhawatirkan oleh Hersri yang mengacu pada kaitan antara pendidikan dan pembinaan bahasa yaitu bahasa nasional itu akan berupa kerangka teknis yang hidup dalam abstraksi, kemudian akan menjadi asing di tanah air sendiri, dan bukan pula mustahil- bahkan dianggap sebagai bahasa kolonisator atas negeri sendiri (1981:88).

Melalui jurnalisme, proses revitalisasi bahasa Indonesia dapat dilakukan dengan intensif. Jurnalisme merupakan sebuah institusi terpenting yang berurusan dengan bahasa secara profesional. Dalam hal ini, jurnalisme tidak tertandingi oleh institusi mana pun, karena intensitasnya dan ekstensinya dalam menggunakan bahasa. Dalam penggunaannya itu berarti jurnalisme mengembangkan bahasa, yang pada gilirannya turut memberikan karakteristik tertentu serta menetukan pada tahap mana peradaban suatu bangsa berada. Menurut de Fleur (1989) jurnalisme sangat berperan dalam mengembangkan bahasa antara lain; mengembangkan kata-kata baru beserta makna asosiatifnya, memperluas makna 
dari istilah-istilah yang ada; mengganti makna lama dengan makna yang baru, dan memantapkan konvensi makna yang telah ada dalam suatu sistem bahasa.

Revitalisasi bahasa Indonesia dapat pula bermakna pemilihan bahasa Indonesia di atas bahasa lain untuk mengekspresikan ide dan perasaan. Pemilihan terhadap bahasa Indonesia di atas bahasa lain juga mencerminkan pandangan hidup dan sikap budaya masyarakat bahasa. Orang Indonesia sebaiknya mencintai bahasa nasionalnya dan belajar menggunakannya dengan kebanggaan dan kesetiaan. Sikap bahasa seperti itulah yang membuat orang Indonesia dapat berdiri tegak di dunia ini yang dilanda arus globalisasi, dan tetap dapat mengatakan dengan bangga bahwa orang Indonesia menjadi bangsa yang berdaulat, tuan di tanahnya sendiri, yang mampu menggunakan bahasa nasionalnya sendiri untuk semua keperluan modern. Siapa lagi yang akan menjaga bahasa dan negara ini kalau bukan masyarakat pengguna bahasa Indonesia. Jikalau terpaksa harus menyerap unsur-unsur bahasa asing ke dalam bahasa Indonesia, tentu harus mengacu pada Pedoman Pengindonesiaan Nama dan Kata Asing (1995). Pedoman cara dan kaidah dalam menyerap kata dan istilah asing adalah (a) kata dan istilah asing dapat diserap melalui penerjemahan; dan (b) kata dan istilah asing juga dapat diserap melalui penyesuaian ejaan. Penyesuaian ejaan dilakukan dengan mengutamakan bentuk tulisnya tanpa mengabaikan lafalnya. Norma-norma tersebut telah ditetapkan oleh pemerintah melalui Badan Bahasa Jakarta.

\section{Simpulan}

Revitalisasi bahasa berkaitan erat dengan sikap pemakai bahasa Indonesia terhadap bahasa Indonesia. Melalui ketiga komponen sikap, manusia mencoba dan menduga bagaimana sikap masyarakat Indonesia terhadap bahasa Indonesia. Pemilihan terhadap bahasa Indonesia di atas bahasa lain juga mencerminkan pandangan hidup dan sikap budaya masyarakat bahasa. Orang Indonesia sebaiknya mencintai bahasa nasionalnya dan belajar menggunakannya dengan kebanggaan dan kesetiaan. Sikap bahasa seperti itulah yang membuat orang Indonesia dapat berdiri tegak di dunia ini yang dilanda arus globalisasi, dan tetap dapat mengatakan dengan bangga bahwa orang Indonesia menjadi bangsa yang berdaulat, tuan di tanahnya sendiri, yang mampu menggunakan bahasa nasionalnya sendiri untuk semua keperluan modern. Dengan sikap seperti itu, Bahasa Indonesia dapat tetap terjaga.

\section{Daftar Pustaka}

Alwi H, Dardjowidjojo S, Lapoliwa H, \& Moeliono AM (1998) Tata bahasa bahasa Indonesia, Edisi Ketiga. Jakarta: Perum Balai Pustaka.

Anderson B (1982) Sembah-sumpah: politik bahasa dan kebudayaan Jawa dalam bahasa dan kekuasaan. Prisma XI.

Chaer A \& Agusta L (1995) Sosiolinguistik perkenalan awal. Jakarta: Rineka Cipta.

DeFleur ML \& Sandra Ball-Rokeach (1989) Theories of mass communication, 5 th Edition. New York: Longman.

Lambert WE (1967) A Social psichology of bilingualism. Journal of Social Issues 23. 91-109.

Halim A (1978) Sikap bahasa dan pelaksanaan kebijaksanaan bahasa nasional. Pengajaran Bahasa dan Sastra Tahun VI, No. 6. 11-26.

Hersri (1981) Wanita: Alas kaki di siang hari, alas tidur di waktu malam. Prisma Tahun X/7 Juli:88.

Garvin PL \& Mathiot M (1968) The urbanization of Guarani language: problem in language and culture. Dalam Fishman (ed). Reading in the sociology language. Paris: The Hague.

Moeliono A (1981) Pengembangan dan pembinaan bahasa Indonesia: ancangan alternatif dalam perencanaan bahasa. Jakarta: Djambatan.

Soedjatmoko (1996) Bahasa dan transformasi bangsa. Dalam: Yudi Latif \& Idi Subandy Ibrahim (ed). Bahasa dan kekuasaan: politik wacana di panggung orde baru. Bandung: Mizan.

Sugono D (1997) Berbahasa Indonesia dengan benar. Jakarta: Puspa Swara.

Triandis HC (1972) The analysis of subjective culture. New York: John Wiley \& Sons.

Undang-Undang Dasar (1945) Bab XV, Pasal 36.

UU RI (2009) No 24 Pasal 25, Pasal 26, Pasal 28, Pasal 29 Ayat 1. 